\title{
Informed Health Online
}

\section{Derek Richards}

Director, Centre for Evidence-based Dentistry, Oxford, UK

The Informed Health Online website www.informedhealthonline.org/ is produced by the Health Research and Education Foundation, a non-profit-making healthpromotion charity based in Melbourne, Australia. It aims to provide information and tools that enable people to keep up-to-date with reliable, evidence-based information.

Evidence-Based Dentistry (2004) 5, 80-81. doi:10.1038/sj.ebd.6400282

The Health Research and Education Foundation is based on the following principles:

- Good healthcare information should be available free, in major community languages.

- Evidence on the effects of healthcare is essential for informed self-care and professional healthcare.

- Communities have a right of access to information essential for improving and maintaining their health and wellbeing.

- Health professionals have a right of access to information that is essential to offering the best advice and care.

In addition to providing information and tools to enable people to keep up-todate with reliable, evidence-based information, the foundation also aims to promote research literacy, encouraging both individual and community use of high-quality research. The website is a development of the Cochrane consumer website and a key goal is to promote the accessibility of health information generated by the Cochrane Collaboration.

The website is laid out well and the main text is clear in black on a white background. Links to the key pages are laid out in a logical order on the left of the page (Figure 1). Buttons at the top of the page allow access to available information by using either an advanced search engine, detailed $\mathrm{A}-\mathrm{Z}$ layout, topic-based expandable tree arrangement, or a site map. There is also a site tips button which is useful for people who are not familiar with the site and web pages.

When accessed on 8 August 2004 the homepage had links to a summary of the new Cochrane review on fissure sealants and an article on meta-analysis

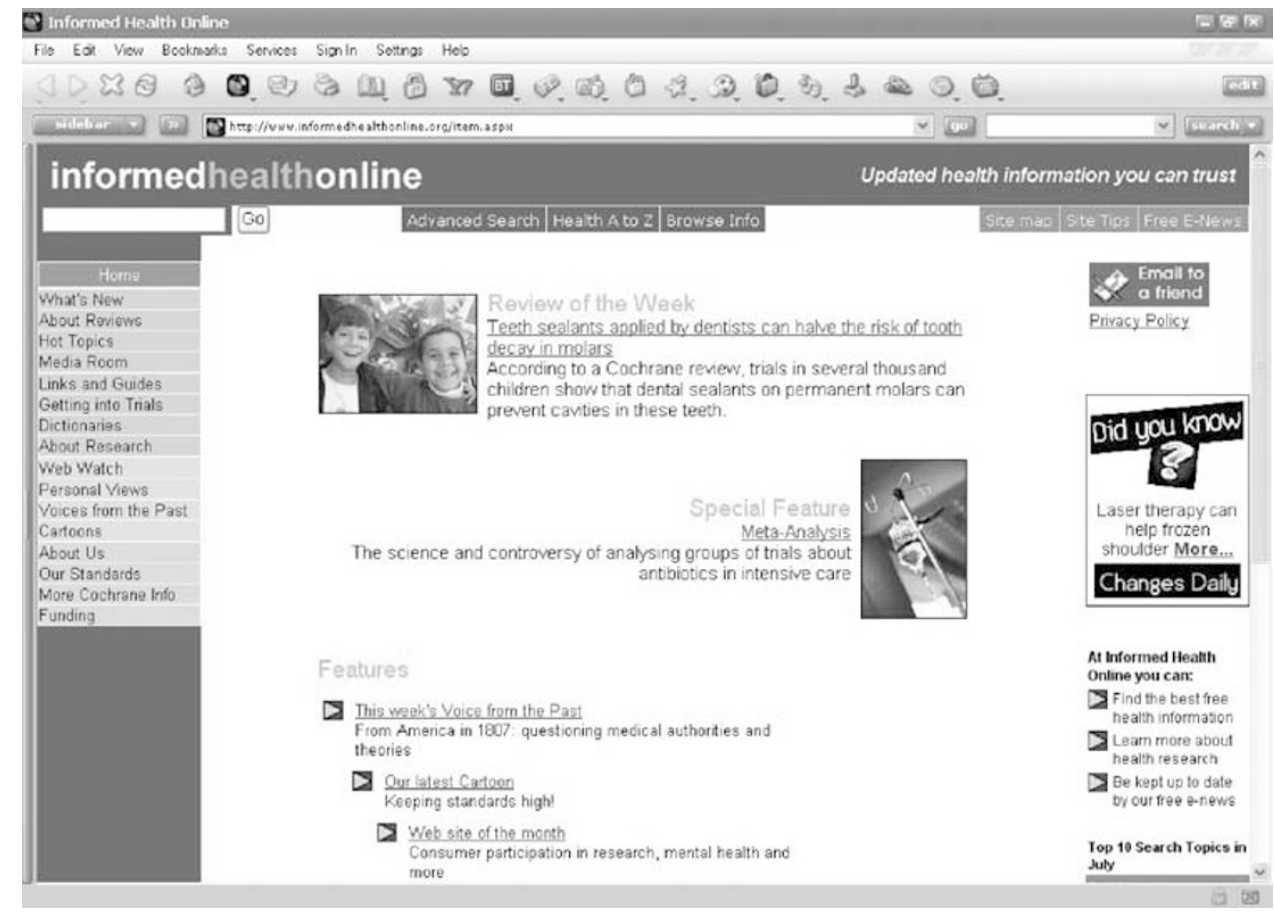

Figure 1. Informed Health Online homepage. 


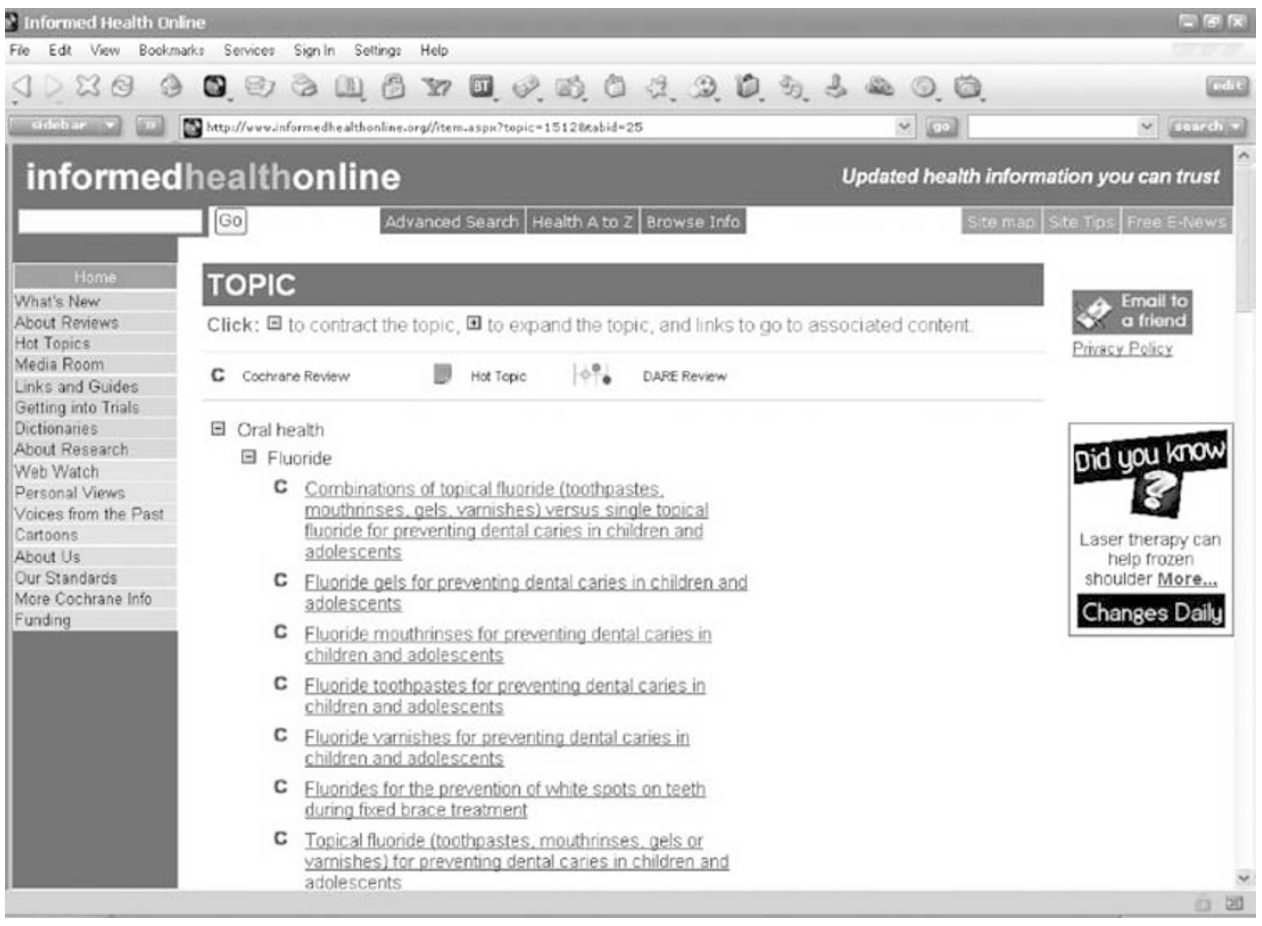

Figure 2. Informed Health Online oral health topic page.

by Alessandro Liberati, Director of the Italian Cochrane Centre.

What's New details the latest changes to the site and About Reviews provides links to articles about the values of healthcare reviews. The Hot Topics link is updated every few weeks. It takes an indepth look at the evidence from Cochrane reviews and other reliable sources, along with background information about the condition of interest, with the aim of developing an integrated library of health information. Currently, it contains a wide range of information for example, on arthritis, severe acute respiratory syndrome or SARS, and reducing anxiety before surgery.

The About Trials link provides information for consumers about how to find out more on randomised controlled trials and other information, as well as how to join a trial. There is also a link to the Ottawa personal decision guide which can help you make complex decisions.
A link to Dictionaries takes you to a page that provides simple definitions of research terms. The list is fairly extensive and it is a useful extension to the glossary that we provide here in Evidence-based Dentistry. Indeed, several of the definitions that we use in our glossary are based on these definitions.

The Oral Health page provides links to simple summaries of all of the Cochrane Reviews published to date by the Cochrane Oral Health Group (Figure 2).

The website is targeted at healthcare consumers and there is currently an article on the Personal Views page by Allan Pinches entitled, "What's in a word? The consumer label". This considers whether we are consumers, patients, users, or people living with condition $X$. The site is, however, a useful resource for both patients and professionals, providing high quality information to each group. The website also conforms to the Health on the Net (www.hon.ch) guidelines about reliability and credibility of health information, as well as ethics in transparency and privacy.

One drawback is that it is currently only available in English, but the Foundation is working with translation partners to identify resources that will assist in the translation of Informed Health Online into major community languages. Funding for Informed Health Online comes from grants and provision of health information, including our partnership with the Cochrane Complementary Medicine Field, for whom they will be producing consumer information and 'e-news' under a grant from the National Institutes of Health in the USA.

Overall this is a well-designed site, with good-quality information and links, which is worth keeping on your list of favourite sites for further visits. 